\title{
Reply to Comments on Science and the Pursuit of Wisdom
}

(Philosophia, Vol. 38, Issue 4, 2010, pp. 667-690; published online, 24 July 2010)

\section{Abstract}

In this article I reply to comments made by Agustin Vicente and Giridhari Lal Pandit on Science and the Pursuit of Wisdom (McHenry, 2009). I criticize analytic philosophy, go on to expound the argument for the need for a revolution in academic inquiry so that the basic aim becomes wisdom and not just knowledge, defend aim-oriented empiricism, outline my solution to the human world/physical universe problem, and defend the thesis that free will is compatible with physicalism.

I am very grateful to Agustin Vicente and Giridhari Lal Pandit for their comments on Science and the Pursuit of Wisdom (McHenry, 2009), for the appreciative things they say about my work, and for taking the trouble to subject it to critical scrutiny. ${ }^{1}$ In my reply, I take the two essays in turn.

\section{Philosophy}

Agustin Vicente begins by remarking that my work is very different from much contemporary philosophy in that, whereas most philosophers engage in puzzle solving, I tackle "deep, vibrant problems concerning ourselves and the world we live in" (pp. 6312). I cannot help but endorse what Vicente says here, even though I might not express myself in quite his words. I begin with a few, all-too-brief remarks about the two very different conceptions of philosophy, to which Vicente alludes.

Analytic philosophy, in my view, has never recovered from the disastrous idea that the proper basic task of philosophy is to analyse concepts. This is a recipe for intellectual sterility at best, intellectual dishonesty at worst. Built into the meaning of the kind of words philosophers are interested in - mind, knowledge, consciousness, justice, freedom, explanation, reason, and so on - there are various kinds of often highly problematic assumptions, factual, theoretical, metaphysical, evaluative. Instead of imaginatively articulating and critically assessing such assumptions directly, philosophical analysis seeks to arrive at definitive meanings for these concepts as if this can be done in a way which is free of problematic factual and evaluative doctrines. This is a recipe for sterility and dishonesty for, in arriving at such definitive meanings, problematic factual and evaluative doctrines are implicitly decided, but without explicit discussion of these doctrines, and without consideration and critical assessment of alternatives. The whole process is, in other words, profoundly irrational. The classic example of all this is Gilbert Ryle's Concept of Mind, which claims merely to analyse the meaning of mental concepts but which thereby, implicitly, espouses behaviourism even though this is explicitly denied.

It may be objected that analytic philosophy has long moved on from this Rylean conception of its task, and no longer confines itself to conceptual analysis. Maybe so, but my point is that contemporary philosophy has not repudiated fully its analytic past, and is still crippled by it. As a result, it still engages in "puzzle solving", as Vicente attests, and fails lamentably to take up its proper task.

The proper basic task of philosophy is to articulate our most fundamental, general and urgent problems, make clear that there are answers to these problems implicit in much of what we do and think - implicit in science, politics, art, the law, education and so on - 
these answers often being inadequate and having adverse consequences for life and thought in various ways as a result. Philosophy should also try to improve our attempted solutions to our fundamental problems, by imaginatively proposing and critically assessing possible solutions, all the time making clear, where relevant, that different possible solutions have different implications for diverse aspects of life. Analytic philosophy does almost the exact opposite of this. Instead of articulating our fundamental problems and proposing and critically assessing possible solutions, it obscures the urgent need for this activity behind a smokescreen of conceptual analysis or "puzzle solving". Analytic philosophy - contemporary philosophy "in the analytic tradition" - is anti-philosophy. It serves to conceal the urgent need for sustained imaginative and critical exploration of our fundamental problems, and our world suffers as result. We live, as a result, in a profoundly unphilosophical age (despite - or even because of - the busy activity of academic philosophers). Bad ideas have bad affects on our lives, on our world, and these ideas are not even acknowledged, let alone critically discussed, let alone subjected to the attempt to improve them. ${ }^{2}$

If an example is required, I would cite my own work on academia. Our world suffers from a damagingly irrational philosophy of inquiry - knowledge-inquiry - which we have inherited from the past and which still dominates academia today. As a result of being built into the institutional structure of academic inquiry, and because of its gross irrationality, knowledge-inquiry is in part responsible for the development of our current grave global crises, and responsible for our incapacity to cope with them, humanely, intelligently and effectively. In order to learn how to solve these global crises, and thus make progress towards as good a world as feasible, we need institutions of learning rationally devoted to that task. We need what I call wisdom-inquiry. Our long-standing failure to put wisdom-inquiry into practice has had untold damaging consequences for our world. ${ }^{3}$

Here, then, is an example of a bad philosophical idea (knowledge-inquiry) which, as a result of being taken for granted in an important area of human life (our institutions of learning and research), and as a result of its bad character (its irrationality), has multifarious bad consequences for our lives (our current incapacity to learn how to tackle our current grave global problems effectively, intelligently and humanely) - global warming, population growth, the lethal character of modern war, and ultimately the avoidable suffering and death of millions of people being the outcome.

This is a philosophical argument. What emerges is a proposed solution to a profoundly important philosophical problem, namely: What kind of inquiry can best help us make progress towards a genuinely civilized, good, wise, enlightened world? It has been in the literature for over thirty years. And yet academic philosophers, busy with their puzzle solving, have - aside from a few notable exceptions ${ }^{4}$ - ignored it entirely. Few philosophers have even heard of the argument, or of wisdom-inquiry. And without the support - or rather, without even the interest or awareness - of my fellow philosophers, it has proved very difficult indeed to get others to take note: scientists, university administrators, politicians, environmental campaigners, the media, the general public (although there are signs that this may be about to change, as we shall see below).

I have two arguments designed to establish that knowledge-inquiry is damagingly irrational, there being an urgent need to modify it to cure it of its irrationality - the 
outcome being wisdom-inquiry, a kind of inquiry both more rigorous and of greater intellectual and human value than what we have at present.

The first argument appeals to a "problem-solving" conception of rationality. Knowledge-inquiry, when judged from the standpoint of helping to promote human welfare by intellectual means, is so defective that it violates, in a wholesale, structural way, three of the four most elementary rules of rational problem-solving conceivable. Modify knowledge-inquiry just sufficiently to ensure that all four rules are implemented, and we have the first, problem-solving version of wisdom-inquiry as a result.

The four rules in question are:

(1) Articulate and seek to improve the articulation of the basic problem(s) to be solved.

(2) Propose and critically assess alternative possible solutions.

(3) When necessary, break up the basic problem to be solved into a number of specialized problems - preliminary, simpler, analogous, subordinate problems - (to be tackled in accordance with rules (1) and (2)), in an attempt to work gradually toward a solution to the basic problem to be solved.

(4) Inter-connect attempts to solve the basic problem and specialized problems, so that basic problem-solving may guide, and be guided by, specialized problem-solving. ${ }^{5}$

Granted that a basic task of academic inquiry is to help promote human welfare, then the basic problems that academia needs to help us tackle are problems of living, problems of action, not problems of knowledge. It is what we do, or refrain from doing, that enables us to achieve what is of value in life not, in general, what we know. Even when knowledge and technological know-how are vital, as they are, for example, in agriculture or medicine, it is always what this knowledge enables us to do that achieves what is of value to us in life, not the knowledge as such.

Thus, if academic inquiry is to put the above four rules into practice, it must give absolute intellectual priority to (1) articulating problems of living, and (2) proposing and critically assessing possible solutions - possible and actual actions, policies, political programmes, philosophies of life. It must also (3) tackle specialized problems of knowledge, but in such a way that (4) specialized and fundamental problem-solving influence each other.

Knowledge-inquiry puts (3) into practice to splendid effect, thus creating the maze of specialized disciplines of modern academia but, in giving priority to the pursuit of knowledge, fails to put (1) and (2) into practice, and thus fails to put (4) into practice as well. As I have said, three of the four most elementary rules of reason are violated. And this is no mere formal matter. It means knowledge-inquiry fails to do what most needs to be done if inquiry is to help us tackle our global problems effectively and humanely, thus helping us make progress towards as good a world as possible: articulate our global problems, and propose and critically assess possible solutions. It means scientific and technological research are pursued in a way which is dissociated from a more fundamental concern with problems of living, it being almost inevitable that the priorities of research will come to reflect the interests of the wealthy and powerful who fund research, rather than the interests of those whose needs are the greatest, the poor of the earth. 
The second argument against knowledge-inquiry and for wisdom-inquiry appeals to an "aim-pursuing" conception of rationality. It goes to the original source of the problem: the Enlightenment. The philosophes of the French Enlightenment, in particular, had the magnificent idea that it might be possible to learn from scientific progress how to achieve social progress towards an enlightened world. They thought this meant creating social science alongside natural science. This idea was taken up and developed throughout the nineteenth century by figures as diverse as J.S. Mill and Karl Marx, and was built into academia in the early twentieth century with the creation of departments of social science: anthropology, economics, sociology, and so on. The outcome is what we still have, by and large, today: knowledge-inquiry.

The basic idea of the Enlightenment is, as I have said, magnificent, but in developing and applying the idea, the philosophes and those who came after them made disastrous blunders. They botched the job - and it is this that we suffer from today. In order to implement the Enlightenment idea properly, the following three steps need to be got right:

(i) The progress-achieving methods of science need to be correctly identified.

(ii) These methods need to be correctly generalized so that they become fruitfully applicable to any human endeavour, whatever the aims may be, and not just applicable to the endeavour of improving knowledge.

(iii) The correctly generalized progress-achieving methods then need to be exploited correctly in the great human endeavour of trying to make social progress towards an enlightened, wise, civilized world.

Unfortunately, the philosophes of the $18^{\text {th }}$ century Enlightenment got all three steps wrong. And as a result these blunders, undetected and uncorrected, are built into the intellectual-institutional structure of academia as it exists today. ${ }^{6}$

As far as (i) is concerned, scientists and philosophers, from D'Alembert in the $18^{\text {th }}$ century to Popper in the $20^{\text {th }}$ (Popper, 1959,1963 ) have accepted versions of a view I call standard empiricism. This asserts that in science theories are assessed impartially with respect to evidence, no permanent assumption being accepted by science about the universe independently of evidence. Preference may be given to simple, unified or explanatory theories, but not in such a way that nature herself is, in effect, assumed to be simple, unified or explanatory. Standard empiricism is, however, untenable. Theoretical physics persistently accepts unified theories - theories that assert that the same laws apply to all the phenomena to which the theory applies - even though endlessly many empirically more successful but disunified rivals can always be formulated. This means physics makes a big, highly problematic, persistent, metaphysical assumption about the nature of the universe: there is some kind of underlying unity in nature (the same dynamic laws governing all physical phenomena). I go on to argue that, once this is accepted, it becomes clear that we need to adopt a new conception of science, aimoriented empiricism, which represents the problematic assumptions, inherent in the aims of physics, in the form of a hierarchy, assumptions becoming less and less substantial as one goes up the hierarchy, and more and more such that their truth is required for science, or the pursuit of knowledge, to be possible. In this way, a framework of more or less unproblematic, stable aims (or assumptions) and associated methods is created within 
which much more substantial, problematic aims and methods may be critically assessed and, we may hope, improved, as scientific knowledge improves. ${ }^{7}$ There is something like positive feedback between improving scientific knowledge, and improving aims and methods, improving knowledge-about-how-to-improve-knowledge, the key feature of scientific rationality which helps explain the amazing progressive success of science. ${ }^{8}$

As far as (ii) is concerned, failure to identify the progress-achieving methods of science properly has led to a failure to generalize them properly. The correct procedure is to generalize aim-oriented empiricism to form what I call aim-oriented rationality. It is not just in science that basic aims are problematic; this is often the case in life too. Whenever aims are problematic, we need to represent them in the form of a hierarchy of aims, and associated methods, aims becoming less and less specific, and so less and less problematic, as we go up the hierarchy, in this way creating a framework of relatively unproblematic aims and methods within which more specific and problematic aims and methods may be improved as we act.

It is in connection with step (iii), however, that the really big blunder of the traditional Enlightenment was made. The blunder is to suppose that this step involves creating and pursuing the social sciences alongside the natural sciences. But the basic Enlightenment idea is to learn from scientific progress how to achieve social progress towards an enlightened world. This involves getting correctly generalized progressachieving methods of science into social life, and above all into all those institutional and social endeavours seeking to help us make progress towards a better world. In so far as this is the task of social inquiry and the humanities, it means these disciplines need to be developed as social methodology, or social philosophy, and not social science.

The blunder, at step (iii), in short, is to apply progress-achieving methods, generalized from science, to the task of improving knowledge about social phenomena, when actually what ought to have been done is to apply these methods directly to social life, to government, industry, agriculture, economic activity, the law, the media, international relations.

The outcome of implementing steps (i), (ii) and (iii) correctly, I argue, is a new kind of inquiry, wisdom-inquiry, a refinement of what emerges as a result of the first argument, indicated above, which appealed to problem-solving rationality. If the philosophes had clearly articulated and advocated wisdom-inquiry, in the $18^{\text {th }}$ century, and if this had been taken up and implemented subsequently, we might live in a very different world today.

\section{From Standard to Aim-Oriented Empiricism}

Vicente objects to step (i) of the second argument, the step that takes one from standard to aim-oriented empiricism. His objections are, however, not valid.

Vicente accepts the central component of my refutation of standard empiricism, namely that physics persistently accepts unified theories even though endlessly many empirically more successful disunified rivals can always be formulated, but denies that this means physics implicitly accepts a substantial thesis about the universe, namely that it has some kind of unified dynamic structure. ${ }^{9}$ He argues that physics accepts unified theories because it seeks explanatory theories, but this does not commit physics to any metaphysical thesis about the nature of the universe (pp. 634-6). 
Vicente does not quite seem to appreciate the full implications of this criticism. Any accepted fundamental physical theory, T say (Newtonian theory, quantum theory, or the standard model) successfully predicts phenomena $\mathrm{A}$, is ostensibly refuted by recalcitrant phenomena $\mathrm{B}$, fails to predict phenomena $\mathrm{C}$ (because the equations cannot be solved) and fails to predict phenomena $\mathrm{D}$ (because they lie beyond the scope of $\mathrm{T}$ ). A horribly disunified rival $\mathrm{T}^{*}$ can always be formulated which asserts that, for A, everything occurs as $\mathrm{T}$ predicts, and for $\mathrm{B}$ to $\mathrm{D}$ everything occurs in accordance with the established empirical laws for these phenomena. $\mathrm{T}^{*}$ successfully predicts everything $\mathrm{T}$ predicts, is not refuted where $T$ is refuted, and successfully predicts phenomena $C$ and $D$ which $T$ fails to predict. Vicente and I agree, of course, that physics invariably accepts T, and does not even consider theories like $\mathrm{T}^{*}$. But if physics seeks truth, this must mean, I claim, that physics persistently accepts that the truth is, in some way, unified (to the extent, at least, that all theories like $\mathrm{T}^{*}$ are false, whatever their empirical support may be). It is only if the search for truth is abandoned, that one can argue validly that persistent acceptance of unified theories like $\mathrm{T}$ when empirically much more successful rivals like $\mathrm{T}^{*}$ are available does not carry the implication that the universe is being presupposed to be such that theories like $\mathrm{T}^{*}$ are false. Vicente is in effect arguing, then, that explanatory (or unified) theories, like $\mathrm{T}$, are persistently accepted in preference to empirically much better supported theories like $\mathrm{T}^{*}$ because physics is more interested in explanation than truth. Even though a non-explanatory but better candidate for truth, $\mathrm{T}^{*}$ is available, physics persistently accepts the ostensibly refuted, less empirically successful theory $\mathrm{T}$, because it is prepared to sacrifice truth for explanation. ${ }^{10}$

Just conceivably this attitude might have a tenuous plausibility in a purely theoretical part of science, without practical implications, such as cosmology. An explanatory theory, even if refuted empirically, might be more worthy of further exploration and empirical testing than an empirically better supported non-explanatory rival. ${ }^{11}$ But, in a wildly implausible way, Vicente argues that this attitude is to be defended even when practical applications of theories are at issue. Even when we are designing and building bridges, we should base our designs on theories which explain, rather than on empirically better supported theories which do not (pp. 635-6). Suppose, then, we have explanatory laws L (like T) which predict a bridge, that is about to be built, will stand, and nonexplanatory but empirically much better supported laws $\mathrm{L}^{*}$ (like $\mathrm{T}^{*}$ ) which predict the bridge will collapse. Vicente recommends we should proceed on the basis of the predictions of L because these laws explain, even though we have good grounds for holding that $\mathrm{L}^{*}$ are better candidates for truth than L. Suppose, now, that the bridge is built and it collapses, as predicted by L*, and many people die as a result. Vicente in effect holds that it is reasonable for the designers of the bridge to argue, in the resulting trial "We based our design on L rather than $\mathrm{L}^{*}$ because, even though $\mathrm{L}^{*}$ are better supported empirically, and better candidates for truth, L gave a better explanation of why the bridge would stand - although admittedly this explanation was false, as the bridge collapsed, as L* predicted". No one in their right mind would think such a defence is reasonable. It would amount to acknowledging that the bridge designers were more interested in explanation, than in truth and the lives of many people. This reveals graphically the invalidity of Vicente's criticism of my refutation of standard empiricism. The aim of seeking truth is too important to science for it to be sacrificed on the altar of explanation (as Vicente in effect recommends). Persistent scientific acceptance of 
theories like $\mathrm{T}$, even though empirically more successful disunified rivals like $\mathrm{T}^{*}$ are always available, does carry the implication that science accepts, as a part of theoretical scientific knowledge, that the universe is such that disunified theories like $\mathrm{T}^{*}$ are false. This thesis needs to be acknowledged and made explicit within physics, so that it can be critically assessed and, we may hope, improved.

\section{Doubts About Aim-Oriented Empiricism}

Vicente goes on to express doubts about the details of aim-oriented empiricism (AOE). He argues that physicalism, one of the metaphysical theses in the hierarchy of such theses postulated by AOE to be presupposed by modern physics, might be empirically falsified, or at least rejected by science in the future (pp. 636-7). But AOE explicitly acknowledges that this might happen, as Vicente subsequently acknowledges (p. 637), so this hardly amounts to a criticism of AOE, as Vicente also acknowledges (p. 637). At most, he suggests, it casts doubt on the metaphysical status of physicalism. I have three replies to this. First, this is a very minor matter of nomenclature. Second, it is important to distinguish falsifiability and scientific revisability. A thesis may be scientifically revisable (because future accepted scientific theories imply it is false) and yet may not be empirically falsifiable (because no evidence can falsify it). Physicalism, I suggest, falls into this category. Finally, I have suggested that that we should revise what we mean by "metaphysical" so that instead of "unfalsifiable" it means something like "a general, factual thesis about the world that lacks the precision of a law or theory" (see my 1998 , p. 271). The $17^{\text {th }}$ century corpuscular hypothesis has the character of a metaphysical thesis, because of its lack of precision; nevertheless it is falsifiable, and indeed is falsified, by its incapacity to account for phenomena associated with attractive forces, whether gravitational, electric or magnetic.

Vicente goes on, however, to develop a more substantial criticism of AOE. If physicalism, and other theses in the hierarchy of theses of AOE "are just inductively supported generalizations, then it seems that ultimately AOE is compatible with SE" ( $p$. 637). AOE is nothing more than a version of SE - of standard empiricism, that is.

Vicente acknowledges that the top two theses of AOE are "immune to empirical evidence: that the world is partially knowable and that [it is such that] we can learn how to learn about it" (p. 637). But, he goes on, "if the rest of the principles are not, strictly speaking, implementations of these two, but stem from theories and data, then these two principles are disconnected from all the others, and play no substantive role in...science" (p. 637). "AOE could be justly considered a 'standard' empiricist philosophy of science" (p. 638).

But Vicente is simply wrong when he declares that the top two metaphysical principles play no role in science. Without these two top principles, science has no basis for rejecting "aberrant" or grossly "disunified" versions of metaphysical principles lower down in the hierarchy, corresponding to "aberrant" or grossly disunified variants of accepted physical theories which are just as empirically successful as accepted theories, or even more so. Physicalism, for example, is not accepted on purely empirical grounds. We can always formulate disunified rivals to accepted physical theories empirically more successful than the accepted theories and, at the same time, we can formulate disunified rivals to physicalism, which have even more empirical support than physicalism does. These rival disunified versions of physicalism - and the rival empirically successful 
research programmes they support - can only be excluded from science by an appeal to the top two metaphysical theses in the hierarchy of theses of AOE. Thus, these top two theses are very actively associated with science, and cannot be declared to have "no substantive role". Vicente's attempt to show that AOE is a version of SE fails. In fact I have in my work anticipated, and refuted, just such an argument: see, for example, my (2004a, pp. 156-9).

Vicente remarks that it is not clear what the relationship is between theses at different levels (p. 638). I have however discussed this issue at some length: see my (1998, chs. 1, 5 and 6; 2004a, chs. 1 and 2, and appendix; 2005; 2007a, especially ch. 14).

Finally, in criticism of AOE, Vicente argues that one can, and perhaps ought to, reject physicalism and nevertheless retain existing unifying physical theories, and even, in the future, a unified physical "theory of everything". I find the reasons Vicente gives for holding that physicalism is false entirely unconvincing. ${ }^{12}$ Nevertheless, Vicente raises an interesting question: might we validly accept a unified physical "theory of everything" even though we reject physicalism, and even have good grounds for that rejection? The answer is: yes. Suppose everything occurs in accordance with a unified physical "theory of everything" except for some physical processes that occur in the conscious brains of people - an interactionist theory of the mind-brain relationship being true. We would still accept the "theory of everything" as the best fundamental physical theory available, even though we know it is false because it is refuted by complex physical phenomena occurring in conscious brains. This does not refute AOE, however. Physicalism is to be adopted as the best available option at present, at that level in the hierarchy of theses. ${ }^{13}$ AOE does not imply that it is the only metaphysical thesis that makes physics possible. In fact, in Maxwell (1998, pp. 168-72), I list 20 distinct metaphysical doctrines, different from or incompatible with physicalism, which would make physics possible (potentially successful), if true.

All Vicente's objections to AOE, and to my refutation of SE, turn out to be invalid.

\section{Aim-Oriented Rationality and Wisdom-Inquiry}

I am delighted to see that Vicente wholeheartedly supports aim-oriented rationality (AOR) and wisdom-inquiry. Here are a few comments.

Vicente remarks that it is "difficult to think of practical ways of implementing the academic revolution Maxwell advocates" (p. 641). As it happens, my own university, University College London, has had considerable success in putting the first steps of this revolution into practice since 2008, partly inspired by my work, under the heading "UCL Grand Challenges". ${ }^{14}$ David Price, vice-provost for research at UCL, has been instrumental in creating four broad areas of research - global health, sustainable cities, human wellbeing, intercultural interaction - which bring together specialists from diverse fields to develop ideas, techniques and policies capable of helping humanity tackle our current grave global problems. This has been done by provoking interest and enthusiasm, inspiring specialists to take part, and not by commanding academics to participate, as it were. That UCL was put fourth in a recent ranking of universities world-wide may have something to do with the success of the Grand Challenges Programme after less than two years. Somewhat similar developments have taken place at Oxford and Cambridge Universities, ${ }^{15}$ and other UK universities are anxious to learn from UCL's success. It is vital to appreciate that the transition from knowledge-inquiry to wisdom-inquiry does not 
need to happen all at once (which would make it all but impossible to do). It can occur gradually, in stages, and can be led by the enthusiasm of those who see the need for, and the intellectual excitement and opportunities of, the revolution.

Vicente goes on to remark that he is "skeptical concerning the possibility of objectively, or intersubjectively, identifying to the required degree "what is of value for oneself and others"' (p. 641). But this ignores the vital role that AOR can play in helping to resolve this problem. Precisely because our aims, our ideals or values, are profoundly problematic, fraught with disagreement and controversy, we need to represent them as a hierarchy, aims or values becoming less and less specific, problematic and controversial as one goes up the hierarchy. In this way, AOR creates a framework of aims and associated methods that can be agreed on, high up in the hierarchy, within which much more specific, problematic and contested aims or ideals (and associated methods) can be assessed and, we may hope, improved. AOR is designed to help resolve conflicts by separating out what is agreed and uncontroversial from what is contested. It facilitates conflict resolution, but is no magic cure for it. It is vital to appreciate, however, that it is not necessary for there to be general agreement about 'what is of value for oneself and others' before AOR and wisdom-inquiry can get off the ground. A vital task for AOR and wisdom-inquiry is to help us improve our ideas about what is of value, even though we disagree, and persist in disagreeing, about what is of value. ${ }^{16}$

Vicente points out, correctly, that it is extremely difficult to decide what aims for scientific research should be pursued (p. 643). It is precisely because research aims are so deeply problematic that I argue we need a new conception of science, humane aimoriented empiricism, which acknowledges the highly problematic metaphysical, value and political assumptions inherent in the aims of science, and which stresses that science needs to sustain critical discussion at three levels, evidence, theory, and research aims, and not just at the first two, as acknowledged by standard empiricism.

\section{The Human World/Physical Universe Problem}

Vicente next turns his attention to what I have to say about the problem of how our human world - the world as we experience it, containing people, consciousness, free will, meaning and value - can exist embedded in the physical universe. Vicente is critical of my attempts at solving aspects of this problem.

The nub of what I have to say goes back to my first three papers published long ago in 1966 and $1968 .{ }^{17}$ Physics is only about a highly selected aspect of all that exists: that aspect which determines necessarily ${ }^{18}$ (but perhaps probabilistically ${ }^{19}$ ) how events evolve, the causally efficacious aspect, in other words. Physics does not need to refer to perceptual features of things around us, such as colours and sounds as we experience them, or conscious features of our brain processes, in order to predict and explain how physical phenomena evolve. Furthermore, physics cannot predict perceptual or conscious features of things. One does not need to have had any special kind of experience in order to understand any physical concept, but one does need to have had a special kind of experience in order to understand what "red" means (when "red" is used to refer to the perceptual quality the normally sighted see). This establishes that no set of purely physical statements can imply, or predict, the existence of "redness" (the perceptual quality). ${ }^{20}$ Furthermore, if physical theory were extended to incorporate experiential features of things, it would become grotesquely ad hoc, complex and 
disunified, and would, as a result, cease utterly to be explanatory. Being silent about the experiential aspects of things is the price physics pays to develop the beautifully unified and explanatory theories that it has developed - Newtonian theory, classical electrodynamics and the rest.

All this has profound implications for the mind/brain problem. First, it allows us to hold what may be called the "externalist" theory of perception, as opposed to the "internalist" theory; and second, it provides an explanation as to why there cannot be a reductionist scientific explanation for consciousness. I take these two points briefly in turn.

According to the external theory, what we perceive and know about, in the first instance, is things external to us; only in a secondary, subsidiary way do we know anything about our inner experiences - so that all we know about our visual sensation of seeing a red rose is "this is the sort of thing that goes on inside me whenever I see a red rose". According to the internal theory, it is all the other way round: what we directly know about, in perception, is our inner experiences; all perceptual knowledge of external things is derived from more basic knowledge of our inner sensory experiences.

If we assume that the silence of physics about the perceptual features of things around us means that these features don't exist, then we are (more or less) forced to adopt the internalist account of perception. Nothing around us is as we experience it; it is all just physics. Our perceptual experiences are almost entirely deceptive about the real features of things external to us, and can only, it seems, inform us about the real features of our inner experiences - and physics, applied to the physical processes associated with perception, seems to support this view. Our knowledge of things external to us is tentatively inferred from our primary, direct knowledge of our own inner experiences. It follows at once that there is a profound problem about how inner experiences can be related to brain processes, since inner experiences, about which we have direct and secure knowledge, are clearly quite different from neurological or physical processes occurring in our brains. ${ }^{21}$

Adopt the view I have indicated above, and this glaring inner experience/brain processes problem disappears. The silence of physics about the experiential does not mean that the experiential does not exist. We may take the world around us to have all the perceptual features we ordinarily perceive it to have. Grass really is green, and traffic really is noisy. Furthermore, in line with the externalist theory, our knowledge of our inner perceptual experiences is derived from our knowledge of things external us: about my inner visual experience of seeing a red rose all $\mathrm{I}$ know is that it is the sort thing that goes on whenever I see a red rose. I know hardly anything about the nature of my inner experiences, and certainly nothing which conflicts with the thesis that they are brain processes. We may adopt the view that inner experiences are brain processes.

In this way, the view that physics is about only highly selected aspect of reality frees us from the temptation to uphold the internalist theory which, in turn, generates the mind/brain problem in a severe form, and instead enables us to adopt the external theory which, at a stroke, dissolves the most serious, apparent objections to the thesis that our inner experiences are brain processes.

The second way in which the above account of physics helps solve the mind/body problem can be put like this. Ordinarily, our consciousness may not seem too big a mystery to us. It is, after all, what we - in some sense - are. However, invoke our best 
mode of explanation - namely scientific explanation - to improve our understanding of consciousness, and something quite extraordinary happens. Consciousness vanishes, and we are left with the brain, neurons and synaptic junctions, waves of sodium and potassium ions being exchanged across semi-permeable membranes. There is nothing like consciousness in sight. Consciousness must be the most profound of mysteries if, when we invoke our best mode of explanation, far from the nature of consciousness being illuminated, it disappears altogether.

But the above account of physics dissolves this mystery. Physics abstains from referring to experiential features because this is not required in order to succeed at the predictive and explanatory tasks it sets itself; and furthermore physics is obliged to refrain from referring to experiential features in order to develop the beautifully unified and explanatory theories that it does develop. None of this means that it is because consciousness is so inherently mysterious and inexplicable that it cannot be explained and understood by science (or that part of science reducible in principle to physics). There is a straightforward explanation as to why consciousness, the experiential, cannot be explained by science (and I go on to suggest that it can be understood by means of a different mode of explanation and understanding, one which science itself presupposes, which I call "person-to-person" or "personalistic" understanding ${ }^{22}$ ).

The mind/brain problem is, in some respects, like the green grass/physical object problem. There is the one object - the blade of grass. It has, on the one hand, purely physical properties: its physical dimensions, mass, chemical and molecular composition. And it has, on the other hand, its perceptual properties: colour, tactile quality, smell, taste. Physical and perceptual properties are correlated in a highly complex way, but there is no very profound mystery here: science is able to explain why grass is green (in a physical, non-experiential sense of "green") by explaining how and why grass absorbs and reflects light of the range of wavelengths that it does. We can discover what it is physically about the grass that correlates with the perceptual property of greenness. Something analogous, although much more complex, obtains in connection with brain processes and conscious experiences (sensations, feelings, desires, thoughts, imaginings, decisions to act).

There are of course important differences between the two cases. They amount to the following: (a) we know and understand much less about brains than we do about blades of grass; (b) brains are more complex than blades of grass; ${ }^{23}$ (c) conscious experiences correlate, in the first instance, with brain processes construed to be elements of a control system (the conscious brain), which could conceivably be realized by a number of different neurological or physical processes, whereas this does not seem to be the case when it comes to the blade of grass; ${ }^{24}$ (d) in the case of the brain, what is at issue is, not how physical, or "control" or "functional" features of brain processes correlate with perceptual features, but rather with what may be called apperceptual features - features we can only be aware of and know about as a result of having that brain process, or one sufficiently similar in relevant respects, occur in our own brain. ${ }^{25}$

These four differences between the green grass/physical object problem, and the mind/brain problem are important, but not sufficient to create a profound mystery. One might call the above the "green grass/physical object" solution to the mind/brain problem.

Vicente declares that I hold that mental states are contingently identical to physical states (p. 645). I tend to formulate it, however, as the view that there are head processes 
which have both mental and physical features. This does however, I think, commit me to a contingent identity thesis. Of this, Vicente remarks that this "is one of the few things that most philosophers take to be demonstrably wrong" (p. 645). Vicente agrees with the general view that Saul Kripke has demonstrated that identity statements with rigid designators must be necessary. In my view, philosophers are being extraordinarily sheeplike here. They are perhaps over-impressed by Kripke's credentials as a logician. The striking fact is that there is no argument for Kripke's thesis. At the beginning of his Naming and Necessity, Kripke says "I hope that some people see some connection between the two topics in the title" (Kripke, 1986, p. 22). But there is no connection. Whatever shreds of an argument there may be have been decisively refuted in my (2001, Appendix Two, pp. 259-73), in which I also give an anti-Kripkean account of contingent identity. Vicente does not refer to this work, and perhaps has not read it: he just assumes it is wrong. Everyone "knows" Kripke is right, so he must be (not the way to do philosophy).

Vicente goes on to challenge my claim that there can be agency or free will if the universe is physically comprehensible. He invokes Libet's experiments which seem to show that the conscious decision to act comes after the action has been initiated (Libet $e t$ al., 1983). But I, and others, have shown, in my view decisively, that Libet's results do not undermine the reality of free will (Maxwell, 2010, p. 262). Subjects taking part in the experiment freely put their brain in a special state so that some random neurological process will initiate a predetermined action. Free will is exercised in deciding, in effect, to put one's brain into this special state; that the subsequent random fluctuation is not freely initiated is neither here nor there, and that latter action is certainly not characteristic of most freely chosen actions in real life. Vicente also refers to Wegner (2002) as undermining free will, when all it does is to show we may on occasions, or in special circumstances, deceive ourselves about the real reasons for our actions. That we do not always act freely does not mean that we never do.

Vicente concludes his critique by arguing that the two-aspect view I defend cannot overcome the problem encountered by epiphenomenalism: granted physicalism, the physical states of our brains (plus physical states of our body and the immediate environment) must be the cause of our actions, which leaves no room whatsoever for our conscious decisions to act to have a causal role. This objection is decisive against epiphenomenalism, but fails against the "green grass/physical object" solution to the mind/brain problem that I espouse. Epiphenomenalism holds that mental states are distinct from brain states, and play no role in causing brain states to occur: it is, as a result, impossible to see how mental states can play any role in initiating action. The view I espouse holds that brain states and conscious states are but two aspects of processes occurring in our heads. Conscious decisions to act do, thus, play a crucial role in producing and controlling action.

But, Vicente in effect continues, it is the physical features of the head process that play this role, not the mental features, which can have no role to play. Thus the objection goes through.

There is, here, I think, a serious problem. It is one I have struggled to solve in my (2010, ch. 7) to which Vicente refers. Here, I shall make a few crucial points as briefly as I can. 
First, it is clearly illegitimate to require that the non-physical - and thus non-causal mental aspects of brain processes play a causal role in determining actions. To require this is to require a contradiction. Nevertheless it is entirely legitimate to ask: What role do the mental features of brain processes play in initiating and controlling action if everything is causally produced by the physical aspect of brain processes (plus the environment)? What role can the mental features possibly have?

This crucial question prompts another: What exactly is the nature of the mental features of our inner experiences, our inner sensations, feelings, desires, imaginings, intentions, thoughts, decision to act? What is it that we are aware of, in being aware of these things? My answer is that we are aware of the control or functional aspects of the brain processes that are these inner experiences. What I am aware of about what is going on inside me when I see a red rose is the control aspect of the brain process that is my perception of the red rose - that aspect which informs me that there is a red rose before me, and therefore how I need to act to take its existence into account. In becoming aware of feelings, desires, intentions, imaginings, decisions to act, I become aware of the control aspects of the relevant brain processes - the role that these processes have in influencing or guiding my actions. In imagining that I get up from the chair I am sitting in to greet a friend I arrange for neurological processes to occur in my brain that are analogous, from a control or functional standpoint, to neurological processes that would occur in my brain (and I would make occur) were I actually to get up and greet my friend. And when I do get up to greet my friend, I arrange for precisely those neurological processes to occur in my brain required to cause my muscles to contract in consort so as to result in me rising and greeting my friend - but what I know about are the control or functional aspects of these brain processes, not the neurological or physical aspects. We have, in other words, incredibly detailed and precise knowledge of neurological processes occurring in our brain, and an incredible capacity to generate within our brain precisely those neurological processes that need to occur if we are to act as we intend, but what we know about these processes is the control or functional aspect, not the neurological or physical aspect. The latter kind of knowledge, indeed, would be useless from the standpoint of enabling us to find our way around in the world and act as we intend to act. What we need to know, from the standpoint of action, is the control aspect of our head processes.

I have called this view experiential functionalism. ${ }^{26}$ It is not equivalent to orthodox functionalism. ${ }^{27}$ It does not assert that the mental is reducible to the functional and so, ultimately, in principle, to the physical. This is explicitly denied. In having certain kinds of (functionally specified) brain processes occur in our own brains we learn things, about the world, about the realm of possible experience, which we could learn in no other way, such as what it is for something to be blue or red (perceptually), or what it is to experience the visual sensation of blue or red.

Experiential functionalism generalizes, and adds content to, the external theory of perception, discussed above. ${ }^{28}$ In declaring, after J.J.C. Smart, ${ }^{29}$ that what I know about my inner visual sensation associated with seeing a red rose, is merely "this is the sort of thing that occurs in me whenever I do see a red rose", the intention was to show that we ordinarily know very little about the nature of our inner experiences, and thus not enough to exclude the thesis that they are brain processes. Experiential functionalism adds content to this. What we know about our inner perceptual experiences is the control or 
functional aspect of these processes: what we know is what these inner processes tell us about the world around us - as captured in the above Smartian phrase. This is to be generalized. What we ordinarily know about our head processes - in so far as we know anything - is the control or functional aspect of these processes. We have an extraordinarily detailed and precise knowledge of some of our head processes, and an extraordinarily detailed, precise and powerful capacity to create head processes in our brains - but specified, not in neurological or physical terms, but in control terms. ${ }^{30}$

How does this view of what the mental features of brain processes are help solve the crucial question, formulated above: What role do the mental features of brain processes play in initiating and controlling action if everything is causally produced by the physical aspect of brain processes (plus the environment)? The answer can be put like this. Knowledge of the control (i.e. mental) aspects of brain processes is a prerequisite for being in control of what we do (i.e. having free will). As I have said above, knowledge of the neurological or physical aspects of processes going on in our heads would be useless. What we require is what we have: knowledge of the control aspects of head processes, and the capacity to generate those brain processes, construed in control terms, which cause us to do what we intend. Being aware of the mental - that is, the control aspects of our brain processes is just what we need to be aware of in order to find our way around in the world, and do what we want to do. This at least is the case if the following requirement for free will is satisfied.

Fundamental Requirement for Free Will: The control structure of the brain is such that control (or mental) aspects of head processes are correlated with the neurological or physical aspects in such a way that the physical aspect of any head process interacts physically (i.e. causally) with the rest of the brain, the body and the environment in just the way required for the control aspect to be the control item that it is.

If my brain satisfies this requirement then, when I have the experience of seeing a red rose, there really is a red rose before me, causally related to the physical process that is my visual experience; furthermore, this physical aspect interacts physically with the rest of my brain in just the way required for this to be the experience of seeing the rose. For example, it puts my brain into a state such that, if I wish, I can move forward to smell the rose, in just the way required.

Or, to take another example, I decide to walk across the room: if the above requirement is satisfied, then the neurological or physical process corresponding to the conscious decision is such that it interacts with the rest of my brain to cause muscles to contract in an intricately coordinated way so that I do just what I consciously decided to do - I walk across the room.

Analogous correlations hold between conscious thoughts, feelings, desires, beliefs, imaginings on the one hand, and the neurological or physical aspects of these head processes or states on the other.

In a brain that satisfies the fundamental requirement for free will, physics is, one might say, commandeered to be the servant, even the slave, of the human will. Physical processes occur in the brain in just the way required for the person to think her thoughts, reach her decisions for her own reasons, and be in command of her flow of consciousness and her actions. And if, in addition to free will, she has wisdom, then she has the 
capacity to realize what is of value to her and to others in a wide range of different circumstances.

It deserves to be noted that free will, viewed from this perspective, requires physical processes in the brain to occur in accordance with physical law. If some physical processes violated physical law, this would serve only to undermine free will. This point applies to all control systems - even to the humble thermostat, guided missile or robot and not only to those marvels of control systems, those that belong to sentient animals or conscious persons.

It might be objected that it would be little short of a miracle for a brain to exist that satisfies the above fundamental requirement for free will. We human beings do not have perfect free will for all sorts of reasons. Hence, for us, the fundamental requirement is only partially satisfied. This, nevertheless, is still little short of a miracle. In order to understand how this miracle has come to be, we need to attend to biography, history, and ultimately, to evolution. The biological function of the brain is to guide or control the animal to act in its given environment so as to promote survival and reproductive success. Evolution designs brains to be good at controlling animals so as to survive and reproduce - and our free will has evolved from this animal capacity.

According to this view, then, the mental aspects of brain processes are not irrelevant to what really determines what goes on - in the sort of way that epiphenomenalism implies. To the extent that the fundamental requirement for free will is satisfied, physical processes in the brain occur in just the way required for conscious thoughts, feelings, imaginings, perceptual experiences, decisions to act to behave, and to $b e$, the specific conscious processes that they are. The mental (that is, control) aspect specifies what needs to be the outcome, and the physical aspect causes this outcome to occur - just as long as the fundamental requirement for free will is satisfied. Being aware of the mental (that is, control) aspects of our head processes is, according to this view, absolutely essential for being in control - essential for free will. ${ }^{31}$

This concludes my reply to Vicente's "epiphenomenalist" objection. I am immensely grateful to Agustin Vicente for his searching critical scrutiny of my views and if, in the above, I have replied in a somewhat sharp way, I apologize. It came out of a struggle for clarity, not from any hint of hostility.

\section{The New Enlightenment}

I turn now to a consideration of Giridhari Lal Pandit's paper. In it, Pandit gives an account of my arguments for aim-oriented empiricism (AOE), aim-oriented rationality (AOR) and wisdom-inquiry. He concentrates exclusively on the second of the two arguments that I outline above in the section entitled "Philosophy". The first argument is ignored.

There are a few minor details in Pandit's exposition of the argument about which I disagree. Thus on page 650, Pandit says that I hold that it is possible to achieve the transformation of knowledge-inquiry into wisdom inquiry "by improving the aims of science". Much more than that is needed, as I make clear (and as Pandit himself goes on to indicate in quotations from my work). The activity of articulating our problems of living, and proposing and critically assessing possible solutions - possible actions, policies, political programmes - needs to be put at the heart of the academic enterprise. This intellectual activity needs to be pursued in a way that is intellectually more 
fundamental than natural science. The nature of social science needs to be transformed so that it becomes, in the first instance, social methodology or social philosophy. The relationship between natural science and social inquiry and the humanities needs to be transformed, as does the relationship between academic inquiry as a whole, and the social world beyond. The nature of natural science needs to change, so that its intellectual domain comes to consist of three levels of discussion, evidence, theory, and aims, and not just, as at present, the first two. All this involves much more than "improving the aims of science", although that is involved as well.

Again, on pages 655-6, Pandit specifies four steps in my argument for wisdominquiry, which do not correspond to the three steps of my argument, and of the Enlightenment programme, as I have formulated them above. Pandit's fourth step, in particular, I do not recognize at all as the final step in my argument. According to Pandit, it "involves applying the generalized methodology to the explicitly stated metaphysical assumptions of science" (p. 656) whereas, for me, the final step is to apply the generalized progress-achieving methods of science to social life (which Pandit elsewhere does acknowledge).

A rather more serious point is that, on a number of occasions Pandit asks questions which he does not answer, the unanswered question implicitly casting doubt about my work. It is as if Pandit is too polite to state his criticism explicitly, although it would have been much better if he had. Thus, on a number of occasions Pandit asks if my work is really so different from Popper's. The question is not answered, but the reader may be left with the impression that there is not much difference. On page 660, for example, Pandit says "one might wonder whether or how AOE also implies an improvement on Popper's (1982) view of development of physical theory as involving influential 'metaphysical research programmes'", and Pandit goes on to quote Popper on the subject, but leaves the question hanging in the air, not explicitly answered, but with the reader feeling, no doubt, that there is not much difference between the two views. In fact there are major differences, as I make clear in Maxwell (2005 and 2010c).

To begin with, Popper explicitly rejects the argument for AOE: see my (2005, pp. 193 and 234-5, note 5). Popper argues that it can be left to scientists to dismiss empirically successful but grossly disunified or "silly" rivals to accepted theories, not appreciating that these "silly" theories are, according to his own falsificationist methodology, more acceptable than accepted theories. As I put it, "Popper fails to appreciate that it his methodology, not he himself, which needs to declare that silly theories are indeed "silly". The fact that his methodology declares these silly theories to be highly acceptable is a devastating indictment of his methodology. To argue that these silly theories, refuting instances of his methodology, do not matter and can be discounted, is all too close to a scientist arguing that evidence, that refutes his theory, should be discounted, something which Popper resoundingly condemns. The falsificationist stricture that scientists should not discount falsifying instances, ought to apply to methodologists as well!" (Maxwell, 2005, pp 234-5).

Popper's failure to appreciate the validity of the argument for AOE is directly responsible for the key difference between AOE and Popper's "metaphysical research programmes" (MRPs), namely, the scientific status of the metaphysical theses involved. For Popper, the metaphysical theses of his MRPs are all extra-scientific conjectures, in the context of discovery, very definitely not a part of scientific knowledge. " $[\mathrm{T}]$ hey 
may all be said to have been more of the nature of myths, or of dreams, than of science. But they helped to give science its problems, its purposes, and its inspiration" (Popper, 1982, 165). For AOE, accepted metaphysical theses are very definitely items of theoretical scientific knowledge, more securely established, indeed, than accepted physical theories. (Physicalism, which asserts, in effect, that the true theory of everything is unified, implies that all fundamental physical theories which are limited in scope, and are not theories of everything, are false. This includes our current best physical theories, general relativity, quantum theory, and the standard model. In addition, empirically successful theories that clash with physicalism are to be rejected.) A further difference between Popper's MRPs and AOE is that there is no hint of the hierarchy of metaphysical theses of AOE in Popper's MRPs. This engenders the further difference that, whereas AOE is a meta-methodology, which provides the means for metaphysical theses and associated methods to be improved with improving scientific knowledge, so that there is something like positive feedback between improving knowledge, and improving-knowledge-about-how-to-improve-knowledge, Popper's MRPs provides nothing of the kind, the aim and methods of Popper's falsificationist methodology being permanently fixed.

These differences account for the many improvements of AOE over Popper's MRPs (contrary to Pandit's implicit suggestion that there are none). As I have argued at length elsewhere, AOE solves the fundamental problems in the philosophy of science of induction, simplicity, verisimilitude, and the nature of scientific method. ${ }^{33}$ Furthermore, AOE has important implications for science itself, which Popper's conception of the MRP does not have. There is a big increase in the content of scientific knowledge and understanding (physicalism becoming a part of scientific knowledge). AOE provides theoretical physics with a rational (if fallible) method of discovery, something Popper held could not exist. ${ }^{34}$

There is a much more serious implicit criticism in Pandit's paper, left hanging as an unanswered, or only partially answered, question. Pandit asks (p. 657):

(1) Can science itself provide the resources, e.g., values, without which it is not possible to improve its problematic aims?

(2) Does scientific progress invariably provide the context, or the standard frame of reference, for all other kind of progress that mankind is capable of in different fields of life?

(3) And can science and technology provide solutions to any current or future problems that arise from the adverse impact human activities have on Earth's ecosystems on the one hand and on the future generations on the other?

In asking these questions, Pandit implies, or at least strongly suggests, that I answer "yes" to all three. For otherwise, why would Pandit declare "There arise three basic issues which demand our urgent attention" immediately under the heading "Maxwell's Defence of Aim-Oriented Empiricism and Wisdom Inquiry"? Once again, it would have been much better if Pandit had come out stating explicitly that what I propose does have these implications, which deserve to be rejected, this in turn casting doubt on what I advocate. 
It is I hope clear from what I have already said that my "from knowledge to wisdom" programme does not imply "yes" for any of (1), (2) or (3). As far as (1) is concerned, I have argued, from the outset, that what values influence research aims and priorities cannot possibly be left to scientists to decide: scientists and the public need to engage in cooperative discussion about aims and priorities of research. As far as (2) is concerned, I do argue that there are things to be learnt from scientific progress about how to go about making progress in other areas of life, but to say that is not to say that "scientific progress invariably provides the context, or the standard frame of reference, for all other kind of progress". And the whole rationale behind wisdom-inquiry is that science and technology cannot provide solutions to all our future problems - indeed, in a sense, cannot provide solutions to any problem of living, it always being what we do, or refrain from doing, that solves a problem of living. (Science and technology often help, but also make possible the creation of our global problems.) Wisdom-inquiry stresses that we need to put imaginative and critical exploration of problems of living at the heart of academia precisely because science and technology cannot solve all our problems (or, in a sense, any of them).

From where, then, did Pandit get this idea that my "from knowledge to wisdom" revolutionary thesis answers "yes" to all three questions? Lurking in Pandit's essay, implicit, influential but unstated, there is, I believe, a very serious misunderstanding about what it is that I am advocating. I say this with some confidence because, in a contribution to the Friends of Wisdom Newsletter, Pandit has stated this misunderstanding in a thoroughly explicit way. He writes of what I am advocating "This approach has two immediate consequences: First, that every activity other than science could in principle be reduced to scientific activity and, secondly, that every problemsolving activity outside science could be brought within the purview of the rules of rational scientific problem-solving" (Pandit, 2010, p. 34).

But this constitutes a very serious distortion of what it is that I am advocating. Far from arguing that every activity other than science could be reduced to scientific activity, I argue, rather that, even within academia, science needs to be removed from its throne of intellectual supremacy, and relegated to a subsidiary, secondary role, the primary academic activity being the non-scientific one of articulating problems of living and proposing and critically assessing possible solutions - possible and actual actions, policies, political programmes, philosophies of life, all very different from claims to knowledge, let alone scientific claims to knowledge. Science needs to be set within the framework of the pursuit of wisdom, definitely not, primarily, a scientific enterprise (not even the enterprise of acquiring knowledge). Far from reducing life to science, I argue that life, and the problems of living, are more fundamental than science and the problems of knowledge.

I do argue, it is true, that all worthwhile human endeavours with problematic aims may have something important to learn from scientific progress, but this does not involve reducing these endeavours to science, and does not involve bringing them "within the purview of the rules of rational scientific problem-solving" either. What it does involve is putting aim-oriented rationality (AOR) into practice, but AOR is not scientific method; it is not even a generalization of scientific method as currently understood (namely standard empiricism). AOR is rather a generalization of aim-oriented empiricism (AOE) - a generalization of scientific method as it ought to be implemented in science, not as it 
is implemented, at present. But the crucial point is that AOR is a generalization of AOE; AOR is very definitely not the same thing as AOE itself. It is not scientific method.

And what does AOR imply? That, whenever we pursue problematic aims - as we almost always do - we should represent these aims in the form of a hierarchy of aims, thus providing ourselves with a framework of relatively unproblematic aims and associated methods (high up in the hierarchy) within which much more specific, substantial and problematic aims and associated methods (low down in the hierarchy) can be critically assessed and improved, in part in the light of the success and failure of what we do - in the light of what we enjoy and suffer. If we had built AOR into our social world thirty or forty years ago, when I first began to write about these matters, we might have discovered how to avoid global warming, the disastrous war on terrorism of the last decade, ${ }^{35}$ and the recent banking crisis - all of which have come about through failing to appreciate the problematic character of basic aims. Even the Israel/Palestine conflict might now be resolved. ${ }^{36}$ Does Pandit really think we should refrain from attempting to put AOR into practice in life because, even though it is what we need to do if we are to realize what is genuinely of value, it involves implementing methods generalized from those science ought to implement?

It is clear from the above quotation from his contribution to the Friends of Wisdom Newsletter that Pandit has profoundly misunderstood what it is that I am advocating. It is this misunderstanding that has prompted him to ask the above questions, (1) to (3), and assume I would answer "yes" to all three. It is unfortunate that Pandit has not spelled out his criticisms more explicitly: that would have made the task of revealing the underlying misunderstanding much more straightforward.

\section{References}

Dennett, D., 1991, Consciousness Explained, Allen Lane, London.

Friedman, M., 1974, Explanation and Scientific Understanding, Journal of Philosophy, vol. 71, pp. 5-19.

Jackson, F., 1982, 'Epiphenomenal Qualia', Philosophical Quarterly 32, 127-136. 1986, 'What Mary didn't Know', Journal of Philosophy 83, 291-295.

Kitcher, P., 1989, Explanatory Unification and Causal Structure, in P. Kitcher and W. C. Salmon (eds.), Scientific Explanation, Vol. XIII of Minnesota Studies in the Philosophy of Science, University of Minnesota Press, Minneapolis, pp. 428-448.

Kripke, S., 1986, Naming and Necessity, Blackwell, Oxford.

Lane, N., 2009, Life Ascending, Profile Books, London.

Libet, B., Gleason, C. A., Wright, E. W., \& Pearl, D. K. (1983). Time of conscious intention to act in relation to onset of cerebral activity (readiness-potential). The unconscious initiation of a freely voluntary act. Brain 106, pp. 623-642.

Maxwell, N., 1966, 'Physics and Common Sense', British Journal for the Philosophy of Science 16, pp. 295-311. ,1968a, 'Can there be Necessary Connections between Successive Events?',

British Journal for the Philosophy of Science, vol. 19, pp. 1-25. , 1968b, 'Understanding Sensations', Australasian Journal of Philosophy, vol. 46, pp. 127-146.

1972a, 'A Critique of Popper's Views on Scientific Method', Philosophy of Science,

39, pp. 131-52 (reprinted in A. O'Hear, ed., 2004, Popper: Critical Assessments of Leading 
Philosophers, Vol. II, Routledge, London, pp. 463-487).

1972b, 'A New Look at the Quantum Mechanical Problem of Measurement', American Journal of Physics 40, pp. 1431-5.

1974, 'The Rationality of Scientific Discovery', Philosophy of Science, 41, pp.

123-53 and 247-95.

, 1976a, What's Wrong With Science?, Bran's Head Books, Frome $\left(2^{\text {nd }}\right.$ edition,

2009, Pentire Press, London).

, 1976b, 'Towards a Micro Realistic Version of Quantum Mechanics, Parts I and

II', Foundations of Physics 6, pp. 275-92 and 661-76.

1980, 'Science, Reason, Knowledge and Wisdom: A Critique of Specialism',

Inquiry 23, pp. 19-81.

, 1982, 'Instead of Particles and Fields', Foundations of Physics 12, pp. 607-31.

1984, From Knowledge to Wisdom: A Revolution in the Aims and Methods of

Science, Basil Blackwell, Oxford, 1984; $2^{\text {nd }}$ edition Pentire Press, London, 2007. 1988, 'Quantum Propensiton Theory: A Testable Resolution of the Wave/Particle

Dilemma', British Journal for the Philosophy of Science, 39, pp. 1-50.

1992a, 'What Kind of Inquiry Can Best Help Us Create a Good World?',

Science, Technology and Human Values 17, pp. 205-27. 1993a, 'Induction and Scientific Realism', British Journal for the Philosophy of

Science 44, pp. 61-79, 81-101 and 275-305.

1994, 'Particle Creation as the Quantum Condition for Probabilistic Events to Occur',

Physics Letters A 187, pp. 351-355.

1998, The Comprehensibility of the Universe: A New Conception of

Science, Oxford University Press, Oxford (paperback ed., 2003).

2000a, 'Can Humanity Learn to become Civilized? The Crisis of Science

without Civilization', Journal of Applied Philosophy, 17, pp. 29-44.

2000b, 'A new conception of science, Physics World 13, No. 8, pp. 17-18.

2000c, 'The Mind-Body Problem and Explanatory Dualism', Philosophy, vol.,

75 , pp. 49-71.

, 2001, The Human World in the Physical Universe: Consciousness, Free Will

and Evolution, Rowman and Littlefield, Lanham, Maryland.

, 2002a, 'The Need for a Revolution in the Philosophy of Science', Journal for

General Philosophy of Science 33, pp. 381-408.

, 2002b, 'Karl Raimund Popper', in British Philosophers, 1800-2000, edited

by P. Dematteis, P. Fosl and L. McHenry, Bruccoli Clark Layman, Columbia, pp. 176-

194. See also http://philsci-archive.pitt.edu/archive/00001686/.

, 2004a, Is Science Neurotic?, Imperial College Press, London.

2004b, 'Scientific Metaphysics', http://philsci-archive.pitt.edu/archive/

$00001674 /$

2004c, 'Non-Empirical Requirements Scientific Theories Must Satisfy:

Simplicity, Unification, Explanation, Beauty', http://philsci-archive.pitt.edu/archive/ 00001759/

2004d, 'Does Probabilism Solve the Great Quantum Mystery?', Theoria vol. 19/3, no.

51, pp. 321-336.

2005, 'Popper, Kuhn, Lakatos and Aim-Oriented Empiricism', Philosophia 32, nos. 1-4, pp. 181-239. 
,2006a, 'The Enlightenment Programme and Karl Popper', in Karl Popper: A Centenary Assessment. Volume 1: Life and Times, Values in a World of Facts, ed. I. Jarvie, K. Milford and D. Miller, Ashgate, London, pp. 177-190.

, 2006b, 'Three Problems about Consciousness and their Possible Resolution',

PMS WIPS 005, Nov 15, http://www.petemandik.com/blog/?s=maxwell.

2007a, From Knowledge to Wisdom: A Revolution for Science and the

Humanities, Pentire Press, London [2 ${ }^{\text {nd }}$ edition of Maxwell (1984), revised and extended].

, 2007b, 'Can the World Learn Wisdom?', Solidarity, Sustainability, and Non-

Violence, vol. 3, no. 4, April 2007,

http://www.pelicanweb.org/solisustv03n04maxwell.html

, 2007c, 'From Knowledge to Wisdom: The Need for an Academic Revolution,

London Review of Education, vol. 5, no. 2, pp. 97-115.

2007d, 'The Enlightenment, Popper and Einstein', in Knowledge and Wisdom:

Advances in Multiple Criteria Decision Making and Human Systems Management, Y.

Shi et al., (eds.), IOS Press, 2007, pp. 131-148.

2007e, 'The Disastrous War against Terrorism: Violence versus Enlightenment',

Ch. 3 of Terrorism Issues: Threat Assessment, Consequences and Prevention, ed. A.

W. Merkidze, Nova Science Publishers, New York, 2007, pp. 111-133 (available on my website www.nick-maxwell.demon.co.uk).

, 2008, 'Do We Need a Scientific Revolution?', Journal for Biological Physics

and Chemistry, vol. 8, no. 3, September 2008, pp. 95-105.

2009a, 'Are Universities Undergoing an Intellectual Revolution?', Oxford

Magazine, No. 290, Eighth Week, Trinity Term, June, pp. 13-16.

,2009b, 'From Knowledge to Wisdom', in Ideas on the Nature of Science, edited

by David Cayley, Goose Lane Editions, New Brunswick, Canada, 2009, pp. 360-78. ,2009c, 'How Can Life of Value Best Flourish in the Real World?', in Science

and the Pursuit of Wisdom: Studies in the Philosophy of Nicholas Maxwell, edited by

Leemon McHenry, Ontos Verlag, 2009, pp. 1-56.

,2009d, 'Replies and Reflections', in Science and the Pursuit of Wisdom: Studies

in the Philosophy of Nicholas Maxwell, edited by Leemon McHenry, Ontos Verlag,

2009, pp. 249-313.

2009e, 'What's Wrong With Science?', Sublime, Issue 17, 2009, pp. 90-93.

2010a, Cutting God in Half - And Putting the Pieces Together Again: A New

Approach to Philosophy, Pentire Press, London.

2010b, 'A Priori Conjectural Knowledge in Physics', in What Place for the A

Priori, edited by Michael Shaffer and Michael Veber, Open Court, Chicago.

2010c, 'Popper's Paradoxical Pursuit of Natural Philosophy', in Cambridge

Companion to Popper, edited by Jeremy Shearmur and Geoffrey Stokes, Cambridge

University Press, Cambridge.

,2010d, 'Is the Quantum World Composed of Propensitons?', in Probabilities, Causes

and Propensities in Physics, edited by Mauricio Suárez, Synthese Library, Springer, Dordrecht.

McHenry, L., 2009, Science and the Pursuit of Wisdom: Studies in the Philosophy of

Nicholas Maxwell, Ontos Verlag, Frankfurt.

Motion, O., 2009, Eating the Sun, Fourth Estate, London.

Nagel, T., 1974, 'What Is It Like to Be a Bat?', The Philosophical Review 83, pp. 435-50. 
Pandit, G.L., 2010, ‘Aim Oriented Empiricism', Friends of Wisdom Newsletter, Edition

6, http://www.knowledgetowisdom.org/Newsletter\%206.pdf , pp. 30-37.

Popper, K., 1959, The Logic of Scientific Discovery, Hutchinson, London. 1962, The Poverty of Historicism, Routledge and Kegan Paul, London. 1963, Conjectures and Refutations, Routledge and Kegan Paul, London. 1969, The Open Society and Its Enemies, Routledge and Kegan Paul, London. 1982, Quantum Theory and the Schism in Physics, Hutchinson, London.

Smart, J.J.C., 1963, Philosophy and Scientific Realism, Routledge and Kegan Paul, London.

Smith, P. and O.R. Jones, 1986, The Philosophy of Mind, Cambridge University Press, Cambridge.

Wegener, D. (2002). The illusion of conscious will. Cambridge: MIT Press.

\section{Notes}

${ }^{1}$ For an outline of my work, see my initial contribution to Science and the Pursuit of Wisdom, Maxwell (2009c); for my reply to criticisms, see Maxwell (2009d).

${ }^{2}$ See my (1976a, ch. 4) for a lengthier critique of analytic philosophy, along these lines. See also my (2001, ch. 1; 2004a, pp. 103-110; 2007a, pp. 171-6). And see Popper (1959, Preface 1958; 1963, ch. 2)

${ }^{3}$ This argument is spelled out in detail in my (1984) and (2007a). See also my (1976a; $1998 ; 2004 a ; 2010 a)$. For summaries of the argument, see my $(1980 ; 1992 a ; 2000 a$; 2007b; 2007c; 2008; 2009b).

${ }^{4}$ Philosophers who have responded favourably, as well as sometimes critically, to various aspects of my work include Mary Midgley, Leemon McHenry, Mathew Iredale, David Hodgson, Jerry Ravetz, Fred Muller, J.J.C. Smart, Danniel Dennett, George F. Kneller, Noretta Koertge, Margret Grebovicz, Steve Fuller, Margaret Boden, Jeremy Shearmur, Cory F. Juhl, Sherrilyn Roush, Niall Shanks - and, of course, AgustinVicente and Giridhari Lal Pandit.

${ }^{5}$ Much of Karl Popper's work is devoted to stressing the importance of the first two of these rules of rational problem-solving: see, for example, Popper (1963). Popper was too opposed to specialization, however, to give due weight to the importance of rule (3). He did not see that the evils of specialization could be counteracted by putting rule (4) into practice. For Popper's opposition to specialization see Maxwell (2010c).

${ }^{6}$ The blunders of the philosophes are not entirely undetected. Karl Popper, in his first four works, makes substantial improvements to the traditional Enlightenment programme (although Popper does not himself present his work in this fashion). Popper first improves traditional conceptions of the progress-achieving methods of science (Popper, 1959). This conception, falsificationism, is then generalized to become critical rationalism. This is then applied to social, political and philosophical problems (Popper, 1962, 1963, 1969): see Maxwell (2002b). The version of the Enlightenment programme about to be outlined here can be regarded as a radical improvement of Popper's version: see Maxwell (2004a, chapter 3). See also my (2006a; 2007d; 2009e)

${ }^{7}$ This argument, refuting standard empiricism and in support of aim-oriented empiricism, was first spelled out by me long ago in my (1974), the first hints of it in my (1972a). It was further developed and improved in a number of subsequent publications: see my 
(1976a; 1984; 1993a; 2000b; 2002a; 2004b; 2004c; 2005; 2010a, ch. 5; 2010b), and especially, my (1998; 2004a, chs. 1, 2, and appendix; and 2007a, ch. 14).

${ }^{8}$ Physics has made progress because something like aim-oriented empiricism has been implemented in practice. Nevertheless, official allegiance to standard empiricism has had a detrimental impact on science: see my (1998, pp. 26-33; 2004a, ch. 2; 2008).

${ }^{9}$ Vicente refers to Friedman (1974) and Kitcher (1989) as having explicated explanation in terms of unification; he evidently does not know of my decisive refutation of these accounts (Maxwell, 1998, pp. 65-6). For my own account of theoretical unification and explanation in physics, see Maxwell (1998, ch. 4). See also my (2004a, pp. 160-74; 2007a, pp. 373-86),

${ }^{10}$ This point is absolutely crucial. If empirically successful disunified theories, like $\mathrm{T}^{*}$ are persistently ignored in favour of less empirically successful (or even refuted) unified or explanatory theories, like T, this must mean that all horribly non-explanatory, disunified theories, like $\mathrm{T}^{*}$, are just assumed to be false, whatever their empirical success may be, unless concern for truth is abandoned, in which case accepting T-like theories does not carry the implication that $\mathrm{T}^{*}$-like theories are all presupposed to be false. If and only if - the aim of seeking truth is abandoned can one validly argue that one is rationally entitled to accept $\mathrm{T}$ even though $T^{*}$ is a better candidate for truth.

${ }^{11}$ But even in this case, the false, explanatory theory would be tested further in order to develop a new explanatory theory that is a better candidate for truth. The search for truth would not be abandoned, in the way Vicente in effect recommends.

${ }^{12}$ My reply to what Vicente says on pages 637-8 is as follows. Even if physicalism is true, physical theory will always be limited in what it can in practice predict (Maxwell, 1998, p. 33-4); there are no phenomena associated with complex systems, or with life, that provide grounds for holding physicalism is false; the physical is only an aspect of all there is; the fact that living things and persons can be explained and understood nonphysically, in ways not reducible, even in principle, to physical explanation, does not tell against physicalism, as we shall see in a later section; Nancy Cartwright's arguments concerning the limits in principle of physical explanation are invalid.

${ }^{13}$ For reasons for holding physicalism to be the best available option, see my (1998, ch. 5; 2004a, appendix, sections 3 and 6; 2007a, pp. 400-430). I should add that my account of what it means to say that a physical theory is unified reveals that there are endlessly many different versions of physicalism to choose between. A physical theory may be unified in one or other of eight different kinds of way, each of which may have different degrees of unity, from 1 to $\infty$ (Maxwell, 1998, ch. 4; 2004a, pp. 160-74; 2007a, pp. 37386). Corresponding to all possible physical "theories of everything" that are unified in one of these eight different ways, to some degree $\mathrm{N}$, there is a version of physicalism. There are, in other words, as many different versions of physicalism as there kinds and degrees of theoretical unity.

${ }_{15}$ See www.ucl.ac.uk/grand-challenges/.

${ }^{15}$ See Maxwell (2009a).

${ }^{16}$ See Maxwell (1984 or 2007a, chs. 5 and 7; 2004a, chs. 3 and 4; 2010a, chs. 6 and 9).

${ }^{17}$ See my (1966, 1968a and 1968b).

${ }^{18}$ This requires that there can be necessary connections between successive states of affairs, contrary to Hume's view on the matter. For this, see my (1968a; 1998, pp. 141- 
$55)$.

${ }^{19}$ I have, in a long series of papers, argued that probabilism enables us to develop a version of quantum theory which (a) solves the wave/particle problem, (b) provides a fully micro realistic version of quantum theory, free of any need to appeal to measurement, (c) recovers all the empirical success of orthodox quantum theory, (c) but is empirically distinct from the orthodox version of the theory for as yet unperformed experiments: see my (1972b; 1976b; 1982; 1988; 1994; 1998, ch. 7; 2004d; 2010d). Probabilistic physicalism may be the key to solving the problems of, and understanding, the quantum domain.

${ }^{20}$ This argument, usually attributed to Thomas Nagel (1973) and Frank Jackson (1982, 1986) was in fact first spelled out by me in my (1966, especially pp. 303-308; and 1968b, especially p. 127, pp. 134-137 and 140-141). When I drew Thomas Nagel's attention to these publications, he remarked in a letter, with great generosity: "There is no justice. No, I was unaware of your papers, which made the central point before anyone else". Frank Jackson acknowledged, however, that he had read my 1968 paper.

${ }^{21}$ Our inner experiences are private, indubitable, non-spatial, and have all the diverse "mental" features we experience them as having, associated with seeing, hearing, and so on. Brain processes have none of these mysterious "mental" features.

${ }^{22}$ See my (1984, pp. 174-189 and 264-273), or (2007a, pp. 197-213 and 285-294); see also my (2001, pp. 103-112).

${ }^{23}$ Chloroplasts, the minute structures within which photosynthesis occurs, and which give greenness to grass, are however highly complex and intricate in the way they work: see Lane (2009, ch. 3) or Motion (2007, Part One).

${ }^{24}$ It could be argued that the greenness of grass also correlates with a control system, with something "functional", namely the chloroplast functioning as a system engaging in photosynthesis. And it would seem reasonable to hold that the same function may be performed by systems with many different physical structures. No one chloroplast is exactly the same, at a molecular level, as any other, and chloroplasts from different species of plant may differ in more systematic, radical ways, and yet produce the same hue of green. All this just helps my argument, however, in that it serves to draw closer together the green grass/physical object problem, and the mind/brain problem. The control or functional character of the chloroplast is, however, perhaps a somewhat spurious point to appeal to, as non-living things are also green, such as paint. Here, too, however, many very different physical conditions can correspond to the same hue of green. This becomes all the more apparent when one takes into account that the colour one sees depends on conditions of illumination, and on the colour environment. But point (c) in the text is it seems basically correct. Inner experiences correlate, in the first instance, with brain processes construed in control or functional terms, whereas perceptual features need not.

${ }^{25}$ I used the word "apperceptual" in this way in my (1968b, p.143).

${ }^{26}$ See my (2001, p. 123 and 137, note 53.

${ }^{27}$ See, for example, Smith and Jones (1986).

${ }^{28}$ Adopt the internalist theory of perception, and we are driven to adopt a view not so very different from epiphenomenalism, vulnerable to Vicente's objection. For the internalist theory, in contrast to the external theory, implies that our perceptual experiences are very different from brain processes, and thus suggests that mental 
processes, in general, are distinct from brain processes and thus cannot have a role in producing action unless they interact with brain processes, which would involve a violation of physical law and physicalism. Adopt the external theory of perception, and experiential functionalism more generally, and these implications are avoided. Vicente's objection becomes inapplicable.

${ }^{29}$ See Smart (1963, p. 94).

${ }^{30}$ It is this kind of detailed self-knowledge which orthodox functionalists tend to deny apparent, for example, in Daniel Dennett's (1991) denial of the meaningfulness of the question of where, in the brain, consciousness is to be located. This is, in my view, a meaningful and important question, one to which I have given a conjectural answer: see my $(2001, \operatorname{ch} 8)$.

31 My work on the human world/physical universe problem, including the problem of free will, is to be found in Maxwell (1966; 1968a; 1968b; 1984 or 2007a; 2000c; 2001; 2006b; 2009c; 2009d; 2010a).

${ }^{32}$ Popper is obliged to hold this view for, to the end of his life, he held onto his demarcation requirement. This implies that a factual thesis, in order to be a part scientific knowledge, must at least be empirically falsifiable. Metaphysical theses, being unfalsifiable cannot, for Popper, be a part of scientific knowledge - and this includes the metaphysical theses of his MRPs. AOE implies that Popper's demarcation requirement must be rejected.

${ }^{33}$ Maxwell (1998, chs. 4-6; 2004a, chs. 1, 2 and Appendix; 2007a, ch. 14).

${ }^{34}$ For these, and further, fruitful implications of AOE for science and its philosophy, see Maxwell (1998, pp. 26-33; 2004a, ch.2; 2008). For Popper's denial of a rational method of scientific discovery see Popper (1959, p. 31).

${ }^{35}$ See my $(2007 \mathrm{e})$.

${ }^{36}$ See my (2007e, section 5). 